\section{Keeping up appearances: the importance of maintaining health status in COPD}

\author{
Lorcan McGarvey
}

One of the real strengths of the Evaluation of COPD Longitudinally to Identify Predictive Surrogate Endpoints (ECLIPSE) study was that it confirmed something that seemed so obvious that no one ever felt the need to say it! So, we now know that if the patient with COPD sitting in front of you in the outpatient clinic has frequent exacerbations then, guess what? Over time, chances are they will continue to exacerbate. ${ }^{1}$ In the same way, it seems pretty obvious that maintaining or improving the health status of a patient with COPD over the course of any given year would be associated with a better outcome in subsequent years. Well, despite the fact that we have been measuring health status in some shape or form in patients with COPD for almost 30 years, it surprised me that we had no real proof that this was indeed the case. ${ }^{2} 3$ The article by Wilke and colleagues in this month's Thorax finally provides real evidence as to the importance of achieving something that we no doubt have taken for granted as likely to be beneficial. ${ }^{4}$

In this study, the investigators used the St George's Respiratory Questionnaire (SGRQ) total score recorded in ECLIPSE cohort participants at baseline and at the end of year one. Using the SGRQ where a 4-point change is considered the minimum clinically important difference and higher scores reflect worse health status, study participants were categorised as either 1-year improvement (ie, SGRQ score change from baseline through year 1 of $>$ -4 points) or stable (ie, a SGRQ score change of -3.99 to +3.99 points) or 1-year deterioration (ie, a SGRQ score change of $>+4$ points). Then, following those patients up over the subsequent 2 years, they found that those whose health status had improved or remained stable in the first year were less likely to exacerbate, end up in hospital or die compared with patients who worsened, and this finding was independent of age, baseline SGRQ total score and rather curiously previous exacerbation history. So, how does a broad-based measure like

Correspondence to Dr Lorcan McGarvey, School of Medicine, Dentistry and Biomedical Sciences, Queen's University, Belfast BT9 7BL, UK; I.mcgarvey@qub.ac.uk health status influence hard endpoints such as exacerbation rate and mortality, and how should we interpret these findings?

We do know that poor health status is independently associated with adverse outcomes. Patients with COPD with impaired health status tend to do particularly badly as they are more likely to exacerbate and be hospitalised and have lower survival rates than those with better quality of life. ${ }^{5} 6$ We also know that as patients become more symptomatic and suffer more frequent exacerbations or suffer from comorbidities such as depression, their health status is likely to decline. ${ }^{7}$ We also know that in clinical trials where an intervention has improved lung function, reduced symptoms and the frequency of exacerbations, health status has tended to improve as well. ${ }^{9}$

What is it that we measure when assessing health status that is so important? The tools developed for COPD are considered to objectively measure in a standardised manner the impact of the disease on patients' lives. ${ }^{10}$ The SGRQ is one of the most widely used instruments and has three components or domains: symptoms, activity and impact. ${ }^{3}$ The symptom domain relates to frequency and duration of cough and sputum, wheeze and breathlessness. The activity domain measures how physical activity either causes or is limited by breathlessness. The impact domain captures the emotional and psychological factors associated with the disease. However, the relationship between the SGRQ total score and $\mathrm{FEV}_{1}$ is weak, ${ }^{11}$ which is one of the reasons why consensus has moved away from assessing disease severity using lung function alone and towards a composite, including health status, symptoms and exacerbation risk. It was also notable that in this study the ability to maintain or indeed improve health status seemed independent of baseline lung function severity. Furthermore, the relationship between changes in SGRQ total score were mirrored closely in the SGRQ impact domain scores, suggesting that patient outcomes are closely related to how a patient copes and manages with their disease. It is not clear what clinical factors are associated with improving health status.
In a primary-care-based study, which recorded change in total SGRQ over 1 year, one-third of the participants experienced an improvement in health status. ${ }^{12}$ Using logistic regression, the investigators identified factors independently associated with this improvement, and there were no big surprises: those that attended a pulmonary clinic, started new respiratory medication, stopped smoking and completed rehabilitation were more likely to improve. Increasing symptoms (expectoration and breathlessness) or ending up in hospital were independently associated with worsening health status. ${ }^{12}$ The study by Wilke and colleagues does have a few limitations: it was not possible for example to determine the factors that influence the likelihood of a stable or improving SGRQ, and since the participants who improved tended to have poorer baseline health status than those who deteriorated, regression to the mean is likely to have played some part. It also remains to be explained why there was so little difference in outcome between those in the 'no change' category with a mean 1-year change in SGRQ score of +0.3 and the 'improvement' category with an impressive mean 1-year change in SGRQ of -11.8 . None the less, the message of how important it is to achieve health status stability emerges loud and clear from this study.

So, what do the results of this study mean for the patient care? There is no doubt in my mind that we should be actively seeking out those high-risk patients with declining health status. To do this in any clinically meaningful way, health status needs to be measured accurately and regularly, and this needs to be embedded in the routine follow-up of patients with COPD. In practical terms, instruments such as the Chronic Respiratory Disease Questionnaire (CRQ) ${ }^{2}$ and the SGRQ ${ }^{3}$ are not really suitable, but the new shorter questionnaires such as the COPD Assessment Test $^{13}$ and the COPD Control Questionnaire ${ }^{14}$ should make this important task easier.

\section{Competing interests None declared.}

Provenance and peer review Commissioned; internally peer reviewed.

Note The original article by Wilke et al, which this editorial is linked to, was published in Thorax May 2015 issue $(2015 ; 70: 420-5)$

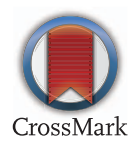

To cite McGarvey L. Thorax 2015;70:813-814.

Published Online First 19 June 2015 


\section{(5) Linked}

http://dx.doi.org/10.1136/thoraxjnl-2014-205697

Thorax 2015;70:813-814

doi:10.1136/thoraxjn-2015-207355

\section{REFERENCES}

1 Hurst JR, Vestbo J, Anzueto A, et al. Susceptibility to exacerbation in chronic obstructive pulmonary disease. Evaluation of COPD Longitudinally to Identify Predictive Surrogate Endpoints (ECLIPSE) Investigators. N Engl J Med 2010;363:1128-38.

2 Guyatt GH, Berman LB, Townsend M, et al. A measure of quality of life for clinical trials in chronic lung disease. Thorax 1987;42:773-8.

3 Jones PW, Quirk FH, Baveystock CM, et al. A self-complete measure for chronic airflow limitation: the St George's Respiratory Questionnaire. Am Rev Respir Dis 1992;145:1321-7.

4 Wilke S, Jones PW, Müllerova H, et al. One-year change in health status and subsequent outcomes in COPD. Thorax 2015;70:420-5.

5 Yorgancioglu A, Havlucu Y, Celik P, et al. Relation between quality of life and morbidity and mortality in COPD patients: Two-year follow-up study. COPD 2010;7:248-53.

6 Domingo-Salvany A, Lamarca R, Ferrer $\mathrm{M}$, et al. Health-related quality of life and mortality in male patients with chronic obstructive pulmonary disease. Am J Respir Crit Care Med 2002;166:680-5.

7 Oga T, Nishimura K, Tsukino M, et al. Longitudinal deteriorations in patient reported outcomes in patients with COPD. Respir Med 2007;101:146e53.

8 Miravitlles M, Ferrer M, Pont A, et al. Effect of exacerbations on quality of life in patients with chronic obstructive pulmonary disease: a 2 year follow up study. Thorax 2004;59:387e95.
9 Calverley PM, Anderson JA, Celli B, et al. Salmeterol and fluticasone propionate and survival in chronic obstructive pulmonary disease. N Engl J Med 2007:356:775-89.

10 Jones PW. Health status measurement in chronic obstructive pulmonary disease. Thorax 2001;56:880-7.

11 Jones PW. Health status and the spiral of decline. COPD 2009;6:59-63.

12 Jones PW, Harding G, Berry P, et al. Development and first validation of the COPD Assessment Test. Eur Respir J 2009;34:648-54.

13 van der Molen T, Willemse BW, Schokker S, et al. Development, validity and responsiveness of the Clinical COPD Questionnaire. Health Qual Life Outcomes 2003;1:13.

14 Monteagudo M, Rodríguez-Blanco T, Llagostera M, et al. Factors associated with changes in quality of life of COPD patients: a prospective study in primary care. Respir Med 2013;107:1589-97. 